\title{
Evaluation of exploitation suitability of enclosing structures of filling stations
}

\author{
Marina Dement'eva ${ }^{1 *}$ \\ ${ }^{1}$ Moscow state university of civil engineering, Yaroslavskoye shosse, 26, Moscow, Russia, 129337
}

\begin{abstract}
The article presents the results of calculating the reliability of enclosing structures of filling station buildings. The aim of the work was to determine the optimal number of inspections of technical condition and to estimate the cost of the operation of the sandwich panel. The problems of searching for hidden failures were analyzed. An overview of the causes and mechanism of wetting the structure was made. An example of a logical-probabilistic structural model for computing the operability for increasing the operational usability of multilayer structures is given. A mathematical model was proposed for determining losses in the selection of various maintenance strategies.
\end{abstract}

\section{Introduction}

The existing automobile fleet of Russia is constantly increasing [1]. To meet the road transport of petroleum products, has been created an extensive network of filling stations and complexes. According to the data of the largest oil companies [2-5], the number of filling stations exceeds 25,000. Construction and reconstruction of filling stations are carried out taking into account the strict requirements of safety, ecology, energy saving and rational equipment placement in the station territory [6-8]. This approach allows increasing the capacity of filling stations, improve the quality and safety of customer service. At present, the largest number of filling stations are built by standard projects with different space-planning characteristics and standard design solutions [9-10].

Climatic features of our country must be taken into account, therefore, regardless of the volume-planning solutions, a heating system and energy-efficient external enclosing structures are required. As a rule, modern service buildings of the gas station have a bearing metal frame made of steel columns on a monolithic plate with self-supporting outer walls, with bearing elements of a coating made of steel I-beams, supported by bearing columns and steel beams from channels. Between the columns along the contour of the building there is a frame for fastening the sandwich panels.

The sandwich panel consists of two sheets of hard material and a layer of insulation between them. All parts of sandwich panels are glued together by hot or cold pressing. Outside, the facade of the building is made of aluminum facing panels. They are painted with powder paint in accordance with the brand and fixed on a metal frame made of galvanized profile. Inside the walls are covered with plasterboard panels also on a metal

* Corresponding author: $\underline{7 d e m @ m a i l . r u ~}$ 
frame made of galvanized profile. As a thermal insulation and soundproofing mineral incombustible insulation is used (Fig. 1). Walls from sandwich panels are also used in the reconstruction of old filling stations [11].

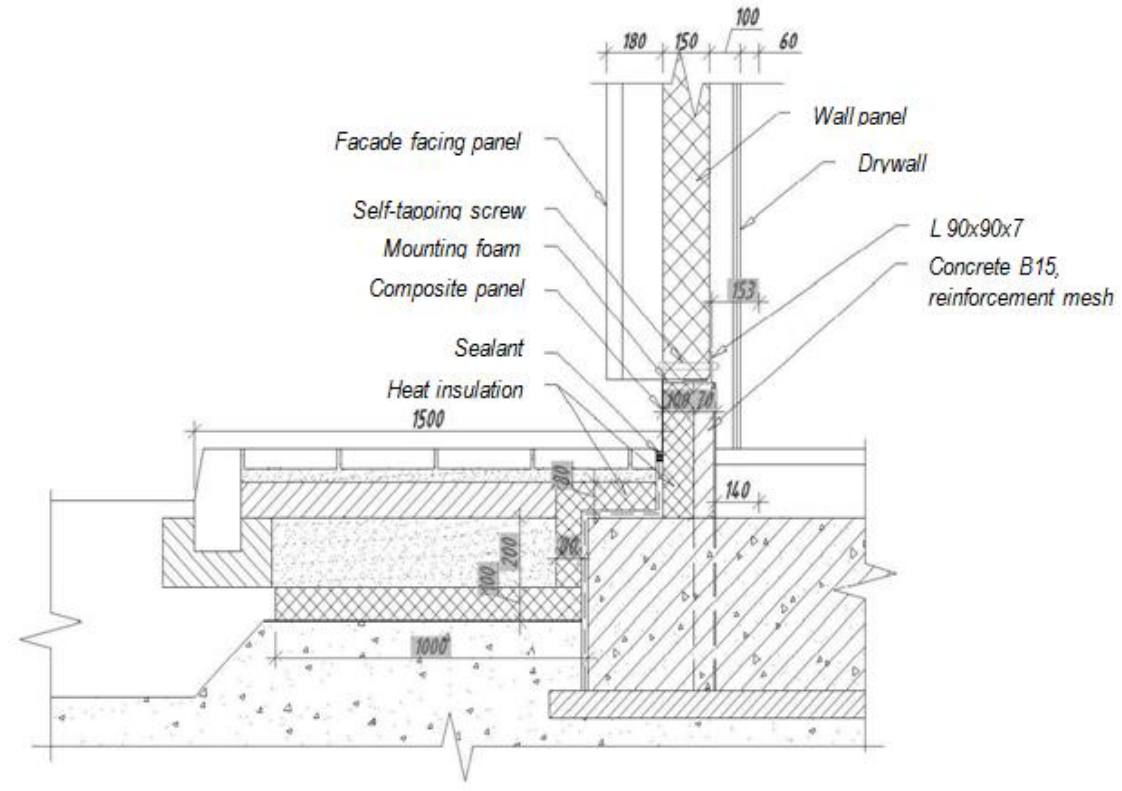

Fig. 1. Knot of interface of an external wall to the base and blind area.

It should be noted that violations in the functioning of sandwich panels are almost impossible to detect without specialized equipment, since they are closed from all sides. Therefore, there is a danger of hidden failures. Such failures include: leakage of roofs at the junction with wall sandwich panels, poor waterproofing of the foundation plate, corrosion of the bearing beams. Failures of this type are dependent, since they lead to the failure of the accompanying building elements and additional energy losses. The detection of hidden failures in buildings of this type has not been investigated previously, and their elimination has not been given due attention in connection with the visual absence of problems. Therefore, the object of research of this work is the process of troubleshooting sandwich panels, as well as the calculation of their trouble-free operation.

The subject of the study is the study of logic-probabilistic modeling techniques that contribute to improving the operational fitness of multi-layer structures. This method of calculating reliability can be applied to any distribution of the time between failures, with any logical structure of the system [12].

The choice for the study of the sandwich panel is not accidental, since the wetting of the insulation leads to a loss of thermal conductivity of the enclosing structures. As a result, the operating costs for heating increase, as well as the discomfort of staff and customers. This means that increases the probability of refusal to provide any services at filling stations and financial losses for companies. In this regard, the problem of assessing the operability of buildings of gas stations and determining the frequency of maintenance and repairs is acute.

The planning of the overhaul of the building, the frequency of inspections and maintenance is based on the planned system developed in the state of centralized planning [13] and does not take into account the actual technical condition of the facility. In addition, the assignment to one or another category of technical condition of building and an assessment of its operational availability, according to the existing normative and technical documentation [14], is a qualitative assessment which depending on the qualification level 
of the appraiser. This approach increases unreasonable operating costs, does not ensure proper reliability and quality of service provision [15].

In addition, the exploitation service should provide timely warning failures, and since such failures are difficult to diagnose, the problem studied in this paper is actual. Thus, the ultimate goal of the study in this work is to justify the periodicity or conditions for assigning buildings of filling stations for maintenance and repair, for example, assessing the operational fitness of sandwich panels.

\section{Experimental section}

One of the objectives of the study was to investigate possible causes of damage to sandwich panels buildings of filling stations. Analysis of information on the problem under consideration $[16,17]$ indicates that one of the main problems in the operation is water. It through the gaps and cracks gets inside the sandwich panels, as a result of which the wet insulation gradually loses its mechanical strength and its heat-insulating properties. The causes of water ingress into the sandwich panel were analyzed. The results are systematized and presented in Table 1.

Table 2. Analysis of damage to the sandwich panel due to moisture at various stages of the life cycle.

\begin{tabular}{|c|c|}
\hline $\begin{array}{l}\text { The reasons for wetting the } \\
\text { insulation of the sandwich } \\
\text { panel }\end{array}$ & Damage to the sandwich panel and wettings mechanism \\
\hline \multicolumn{2}{|r|}{ The period before the start of exploitation } \\
\hline $\begin{array}{l}\text { Marriage of sandwich } \\
\text { panels }\end{array}$ & $\begin{array}{c}\text { Poor bonding of layers of sandwich panels due to deterioration of } \\
\text { equipment at the plant leads to water entering the insulation during rain } \\
\text { or snow }\end{array}$ \\
\hline $\begin{array}{l}\text { Mounting of the supporting } \\
\text { structure of the building } \\
\text { was of poor quality }\end{array}$ & $\begin{array}{l}\text { Inconsistency of the supporting structure of the project (horizontality, } \\
\text { verticality, flatness, parallelism), as a result of which it is impossible to } \\
\text { mount a sandwich panel without gaps, through which moisture gets to } \\
\text { the heat insulation }\end{array}$ \\
\hline $\begin{array}{l}\text { Mounting of the sandwich } \\
\text { panel was of poor quality } \\
\text { or was not completed }\end{array}$ & $\begin{array}{l}\text { The lack of protection of the upper structural element from external } \\
\text { influences during unfinished mounting leads to the humidification of } \\
\text { the insulation through the joints }\end{array}$ \\
\hline $\begin{array}{l}\text { Mounting the ebb of the } \\
\text { roof was of poor quality }\end{array}$ & $\begin{array}{c}\text { The leaky seam between the ebb leads to the flow of water through on } \\
\text { the walls surface, which gets inside the sandwich panel to the heat } \\
\text { insulation }\end{array}$ \\
\hline \multicolumn{2}{|r|}{ The period of exploitation } \\
\hline Flooding of the territory & $\begin{array}{l}\text { Accidents of external engineering networks or significant precipitation } \\
\text { (in the absence of drainage systems or in poor planning of drainage } \\
\text { from the territory) lead to flooding of the territory with moisture } \\
\text { ingress into the sandwich panel }\end{array}$ \\
\hline $\begin{array}{l}\text { Breakthrough internal } \\
\text { pipes of water supply and } \\
\text { heating }\end{array}$ & $\begin{array}{c}\text { Poor mounting or operation of internal engineering systems leads to } \\
\text { water leaks, which floods the interior of the building and leads to } \\
\text { moistening of heat insulation inside the sandwich panel }\end{array}$ \\
\hline Sewerage clogging & $\begin{array}{l}\text { Violation of the rules of use and poor performance lead to the clogging } \\
\text { of pipes, treatment facilities, as a result of water floods the interior of } \\
\text { the building and leads to moistening of heat insulation inside the } \\
\text { sandwich panel }\end{array}$ \\
\hline Traffic Accident & $\begin{array}{l}\text { Hitting a vehicle onto the wall of the building leads to damage to the } \\
\text { facing layer of the sandwich panel, as a result of which moisture enters } \\
\text { the heat insulation }\end{array}$ \\
\hline
\end{tabular}

Identify during the operation of the listed damage is impossible, without dismantling the facing panels from the outside or plasterboard walls inside the building. Elimination of these faults is only possible when replacing the sandwich panel. Therefore, the next task of 
the study was to develop a methodology for calculating the optimal period of maintenance and restoration of the operational fitness of sandwich panels based on the application of logic-probabilistic methods for assessing reliability. To do this, the sandwich panel was presented in the form of a complex model consisting of separate elements, information about the reliability of which makes it possible to assess the reliability of the object as a whole.

The logical and probabilistic model of the operability of an object determines its ability to perform its functions in the case of occasional failures of individual elements or groups of elements and their recovery at a certain time interval of operation. For buildings, engineering systems and their elements, this means the realization of their technical purpose, and for organizational objects - the ability to perform the task. In this case, the concept of working capacity assumes the functioning of the object under normal planned operating conditions. Such a model is sufficient to assess the main property of the reliability of the object - its non-failure. At the same time, operational availability implies safe operation of the facility. Therefore, when investigating the safety of an object, along with non-failure, it is necessary to perform analysis of such properties as persistence, survivability, stability, technical risk, expected damage, real efficiency.

The general logical-probabilistic method of system analysis of the listed properties of safe functioning of an object was carried out in the following sequence:

- development of a structural model of the investigated property of an object, the elements of which are represented by binary events;

- determination of probabilistic parameters of elements (for example, probability of failure-free operation or failure, mean time to failure, average recovery time, occurrence and resistance to exorbitant effects, etc.) and other parameters necessary for calculating required system characteristics;

- setting of logical criteria that determine the conditions for the implementation of the properties of the object under consideration, for example, failure-free operation or failure, ensuring or not ensuring a given level of efficiency, the occurrence or non-occurrence of a certain level of damage in an emergency situation, etc.;

- the construction of the logical function of efficiency in the form of a system of equations that describe the conditions for the implementation of the object of a given logical criterion, depending on the state of all its elements;

- construction of the calculated mathematical model of the investigated property of the system in the form of a polynomial of the probability function;

- calculation of probabilistic indicators of the system properties of reliability and safety of the object under investigation and analysis of their compliance with current state standards and guidelines.

Initially, the process of functioning of all elements of the object is subject to formalization, for each of which data is displayed, under what conditions it implements (or does not realize) its output functions. An element is represented by a set of simple binary events (extreme technical states), consisting in the fulfillment or non-fulfillment of the $i-$ th element of its functions:

$$
X_{i}^{\prime \prime}=\left\{x_{i}, \overline{x_{i}}\right\}
$$

Where $x_{i}-$ the $\mathrm{i}-$ th element performs its functions;

$\bar{x}_{i}-\mathrm{i}$-th element does not fulfill its functions.

Further, the element is represented by a set of complex functional events that determine the "success" of the functioning of the $\mathrm{i}$-th element under the influence of the results of the functioning of other elements logically associated with it:

$$
Y_{i}^{\prime \prime}=\left\{y_{i}, \overline{y_{i}}\right\}
$$

Where $y_{i}$ - are the conditions for the realization of functions by the i-th element;

$\bar{y}_{i}$ - conditions for not implementing functions by the $\mathrm{i}$-th element. 
Graphically, the model is the set of vertices $X$ (binary events $X_{i}^{\prime \prime}$ ) and the set of connecting edges $Y$ (output and providing functions $Y_{i}^{\prime \prime}$ ). Such a representation is a scheme of functional integrity of $F(X, Y)$ of the object under study.

The second step of formalization is the assignment of logical criteria that determine on the scheme of functional integrity the conditions for the realization of the properties of the object under study. Combining all these results, we obtain the desired logical function of the object's operability:

$$
Y_{F}=\left\{y_{i}^{\prime \prime}\right\}=\left\{x_{i}^{\prime \prime}\right\}
$$

The final step of the formalization is to determine the probabilistic parameters of the results of the functioning of the elements and to construct a polynomial of the calculated probability function that makes it possible to analytically determine the distribution of the time of trouble-free operation:

$$
P_{F}=\left\{p_{i}(t), q_{i}(t)\right\}
$$

Where $p_{i}(t)$ - is the probability of the realization of functions by the i-th element;

$q_{i}(t)$ - is the probability of not realizing the functions by the $\mathrm{i}$-th element.

The time to reach the limit state is determined depending on the probability of failurefree operation:

$$
T=\int_{0}^{\infty} \frac{P_{F}(t)}{d t}
$$

Based on this indicator, the maintenance schedule is drawn up. Repair is appointed not according to the normative terms, but taking into account the actual operating time, which takes into account the quality of manufacturing, installation, exploitation and observance of the exploitation conditions of the facility.

In conclusion, an optimal operation plan is drawn up, which will ensure a minimum of losses associated with the cost of inspections and the stay of the system in a state of failure. The object is considered as a system [18], working on the interval [0,T]. The cost of verification will be denoted by $c$ and we will assume that for $t$ units of the system time in the failure state, we carry the loss $v(t)$. The failure of the system after time $T$ no longer causes losses. Let's designate the maintenance strategy:

$$
S_{n}=\left\{t_{k}, k=1,2, \ldots, n\right\}, 0<t_{1}<\ldots<t_{n}<T
$$

Where $S_{n}$ - is the maintenance strategy consisting of $n$ checks on the interval $[0, T]$;

$t_{k}-$ is the moment of time to which $k$ checks took place, $\mathrm{h}$.

Then the mathematical expectation of losses with the chosen maintenance strategy:

$$
\mathrm{E}\left[G\left(S_{n}\right)\right]=\sum_{i=1}^{n} \int_{0}^{T}\left[k \cdot c+v \cdot\left(t_{k}-t\right)\right] d F(t)
$$

Where $G\left(S_{n}\right)$ - losses due to the use of the strategy $S_{n}$, rub.

$k-$ is the actual number of checks;

$c-$ cost of control of the system's operability, rub;

$v$ - cost of damage from the system staying in a state of failure, rub;

$T$ - time of the system stay in the state of failure, $\mathrm{h}$;

$F(t)$-function of system health;

$n-$ is the number of scheduled checks.

\section{Results section}

For the presented in Table. 1 reasons for wetting the sandwich panel were composed of structural and logical models of failure-free operation. The failures of the elements that lead to the object's failure as a whole were analyzed. The formalized model of statement of the problem consists in definition of such composition and form of representation of the initial 
data which allow to carry out logic-probabilistic modeling both manually, and with use of program complexes.

An example of calculating the operability of a sandwich panel for the case of poorquality installation or repair the ebb of the roof is shown in Fig. 3. Damage to the sandwich panel during a technical inspection can be found by visual inspection or instrumental inspection. If there are no damages, then the panel is considered operable. If there is damage, the degree of damage is assessed and a decision is made on the need for repair. If the panel is not repaired, additional measures are assigned.

A complex functional event $Y_{i}^{\prime \prime}$ is defined as the execution of an element of its functions, provided that the "input" of the element receives a signal about the performance of its functions from the elements logically associated with it. If an element is logically connected with several, then a rule is defined, according to which the output function of the element is described for various combinations of signals input to it. For example, the output signal "operability" the panel (element "7" in Fig. 2) will be if two conditions are met:

- the element is operational (in the state $x_{7}$ or $x_{8}$ );

- the input receives a signal about element's operability for different types of inspections (states $x_{3}{ }^{\prime \prime}, x_{4}{ }^{\prime \prime}$ and $x_{9}{ }^{\prime \prime}$ ).

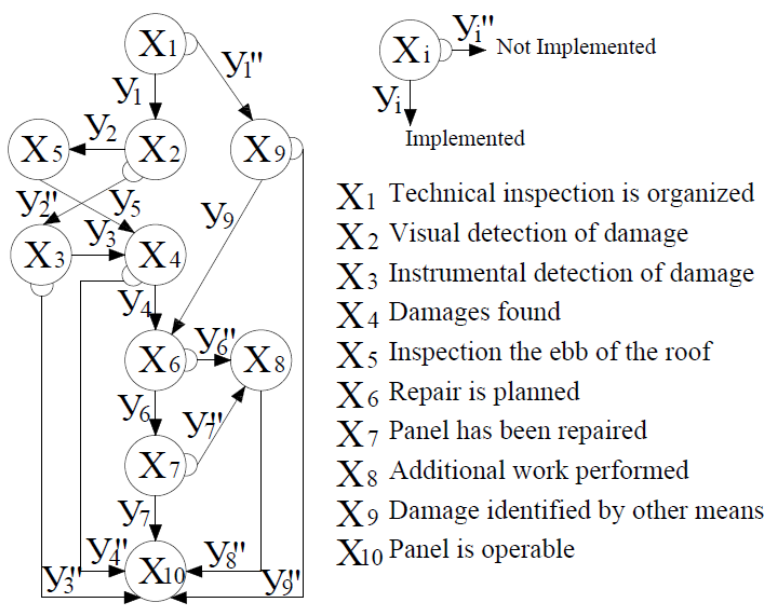

Fig. 2. An example of a logically-probabilistic structural model with non-qualitative mounting or repair the ebb of the roof.

The system of logical equations:

$$
\left\{\begin{array}{l}
Y_{1}=X_{1} \\
Y_{2}=X_{2} \cdot Y_{1} \\
Y_{2}=X_{6} \cdot\left(Y_{4} \vee Y_{9}\right)=X_{2} \cdot X_{1} \\
\cdots \\
Y_{3}^{\prime \prime}=X_{3}^{\prime \prime} \vee X_{2}^{\prime \prime} \vee X_{1}^{\prime \prime} \\
Y_{4}^{\prime \prime}=X_{4}^{\prime \prime} \vee Y_{3}^{\prime \prime} \vee Y_{5}^{\prime \prime}=X_{5}^{\prime \prime} \vee X_{4}^{\prime \prime} \vee X_{3}^{\prime \prime} \vee X_{2}^{\prime \prime} \vee X_{1}^{\prime \prime} \\
\cdots
\end{array}\right.
$$

The desired function of the object's operability:

$$
\begin{aligned}
& Y_{10}=Y_{3}^{\prime \prime} \vee Y_{4}^{\prime \prime} \vee Y_{7} \vee Y_{8} \vee Y_{9}^{\prime \prime}=X_{9}^{\prime \prime} \vee X_{5}^{\prime \prime} \vee X_{4}^{\prime \prime} \vee X_{3}^{\prime \prime} \vee X_{2}^{\prime \prime} \vee X_{1}^{\prime \prime} \\
& \vee\left(X_{9} \cdot X_{7} \cdot X_{6} \cdot X_{5} \cdot X_{4} \cdot X_{3} \cdot X_{2} \cdot X_{1}\right) \vee\left(X_{9} \cdot X_{8} \cdot X_{7} \cdot X_{6} \cdot X_{5} \cdot X_{4} \cdot X_{3} \cdot X_{2} \cdot X_{1}\right)
\end{aligned}
$$

Using the formulas of Boolean algebra we obtain: 


$$
\begin{aligned}
& Y_{F}=\left(X_{9}^{\prime \prime}\right) \vee\left(X_{9} \cdot X_{5}^{\prime \prime}\right) \vee\left(X_{9} \cdot X_{5} \cdot X_{4}^{\prime \prime}\right) \vee\left(X_{9} \cdot X_{5} \cdot X_{4} \cdot X_{3}^{\prime \prime}\right) \vee\left(X_{9} \cdot X_{5} \cdot X_{4} \cdot X_{3} \cdot X_{2}^{\prime \prime}\right) \\
& \vee\left(X_{9} \cdot X_{5} \cdot X_{4} \cdot X_{3} \cdot X_{2} \cdot X_{1}^{\prime \prime}\right) \vee\left(X_{9} \cdot X_{8} \cdot X_{7} \cdot X_{6} \cdot X_{5} \cdot X_{4} \cdot X_{3} \cdot X_{2} \cdot X_{1}\right) \\
& \vee\left(X_{9} \cdot X_{7} \cdot X_{6} \cdot X_{5} \cdot X_{4} \cdot X_{3} \cdot X_{2} \cdot X_{1} \cdot X_{4}^{\prime \prime}\right)
\end{aligned}
$$

We perform the substitution of Boolean variables and logical operations:

$$
\begin{aligned}
& P_{F}=q_{9}+p_{9} \cdot q_{5}+p_{9} \cdot p_{5} \cdot q_{4}+p_{9} \cdot p_{5} \cdot p_{4} \cdot q_{3}+p_{9} \cdot p_{5} \cdot p_{4} \cdot p_{3} \cdot q_{2}+ \\
& +p_{9} \cdot p_{5} \cdot p_{4} \cdot p_{3} \cdot p_{2} \cdot q_{1}+p_{9} \cdot p_{8} \cdot p_{7} \cdot p_{6} \cdot p_{5} \cdot p_{4} \cdot p_{3} \cdot p_{2} \cdot p_{1}+ \\
& +p_{9} \cdot p_{7} \cdot p_{6} \cdot p_{5} \cdot p_{4} \cdot p_{3} \cdot p_{2} \cdot p_{1} \cdot q_{8}
\end{aligned}
$$

The spread in the values of $P_{F}$ for various values of pi and $q_{i}$ is within the error limits (Fig. 3), except when, with a high probability of damage $p_{4}$, the probability of repair $p_{7}$ is small, that is, when the rules of exploitation are violated.

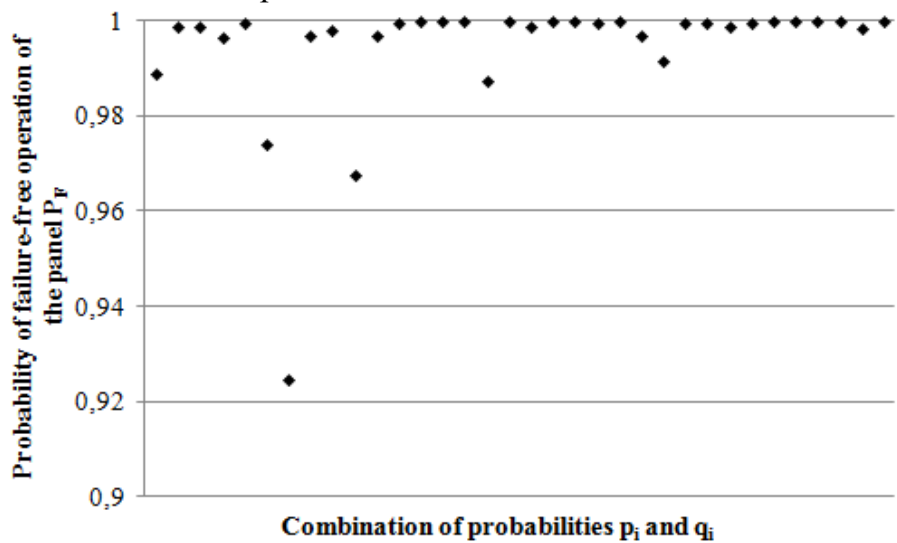

Fig. 3. The dispersion graph of $P_{F}$.

Substituting the upper and lower limits of the probabilities in the formula (7) at a given cost of monitoring and the cost of damage from the electricity consumption for additional heating, due to the loss of sandwich panels associated with damage, we determine the optimal period of maintenance (Fig. 4).

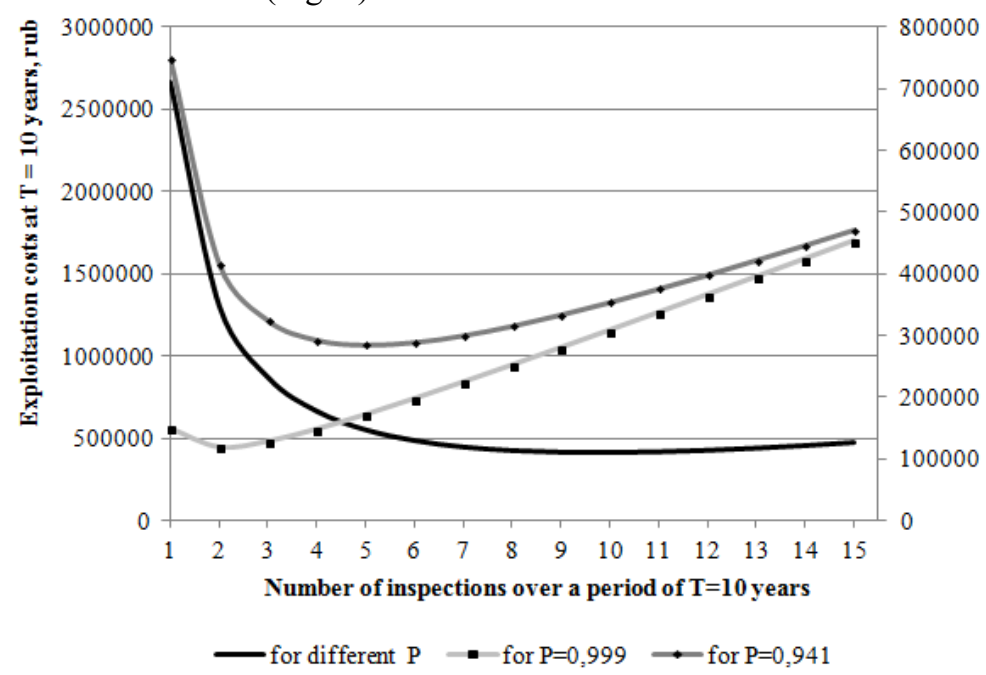

Fig. 4. The schedule for determining the optimum number of inspections $k$ with the minimum operating costs $G\left(S_{n}\right): c=30000 \mathrm{rub} /$ inspection; $v=240000 \mathrm{rub} /$ year. 


\section{Conclusions}

In order to investigate the full range of factors affecting the operational suitability of the filling station buildings and to achieve the set goal in this work, the following was accomplished:

-the existing system of technical operation of the petrol station buildings was analyzed, based on the planned designation of repairs and maintenance;

- the possibility of using logical-probabilistic methods for calculating the reliability of sandwich panels of exterior walls of buildings of filling stations is substantiated, to assess their operational suitability and expediency of performing repair works;

- equation of working capacity and probabilistic function of trouble-free operation of the sandwich panel is made.

To identify damage to sandwich panels, it is required to include measures for troubleshooting into the complex of works on the technical operation of buildings. It is also necessary to establish the frequency of detecting damage to sandwich panels so that take measures to eliminate them.

\section{References}

1. URL: http://www.gks.ru/bgd/regl/b07_13/IssWWW.exe/Stg/d04/17-22.htm (2017)

2. URL: http://www.lukoil.ru/Business/Downstream/PetroleumProductSales/Petroleum ProductRetail (2017)

3. URL: https://www.rosneft.ru/about/Glance/ (2017)

4. URL: http://www.gazprom-neft.ru/products-and-services/for-consumers/filling-stations/ (2017)

5. URL: http://www.benzin-price.ru/zapravka.php?region_id=777 (2017)

6. Russian Standard TR "On the safety of buildings and structures" (2009)

7. Russian Standard TR "About fire safety requirements" (2008)

8. Russian Standard FL "On energy saving and on improving energy efficiency" (2009)

9. Russian Standard SP 118.13330.2012*

10. Russian Standard SP 2.2.1.1312-03

11. URL: http://www.ts-panel.ru/inform/practical_application/stroitelstvo_azs/ (2017)

12. N.N. Gordienko, A.V. Oblienko, E.A. Sushko, Scientific Herald of the Voronezh State University of Architecture and Civil Engineering. Construction and Architecture, 3, 148$153(2010)$

13. Russian Standard RD 153-39.2-080-01

14. Russian Standard GOST 31937-2011

15. M.E. Dement'eva, Housing Construction 8, 1-4 (2007)

16. I. Lepeshkin, Izvestiya MGTU MAMI, 1, 136-147 (2010)

17. N.A. Stashevskaya, A.N. Malov, Y.V. Nikolenko, Bulletin of PFUR, Series: Engineering Research, 2, 18-22 (2011)

18. A.N. Bochkarev, Yu.V. Lonchakov, A.V. Osipov, V.A. Ostashkevich, I.A. Fainburg, Scientific Bulletin of the Moscow State Technical University of Civil Aviation, 121, 116130 (2007) 